\title{
A PETRIFIED SAMPLER: FOREST TIMELINES CAUGHT IN STONE
}

Scientist:

Artist:
Mathew Vanner

Pam McKinlay

\section{FOSSIL WOOD OF THE SOUTHERN SOUTH ISLAND}

\section{Mathew Vanner}

Ancient forests covered much of New Zealand's landscape. These persisted from the time of Gondwana into the modern era. On occasion, the trees forming these forests were buried, either by ash or within an anoxic bog, which protected them from decay, as the first step of fossilisation. Exposure to groundwater with high amounts of dissolved silica, calcite or other minerals was the second step. Over millions of years, this fluid flowed through the dead trunks, replacing the organic tissue with these dissolved minerals, turning them to stone.

Eventually, after millions of years, they have been brought back to the surface. Though much of the fossil wood is found within coal seams, some samples were collected from marine sediments, river gravels, silcrete or breccia.

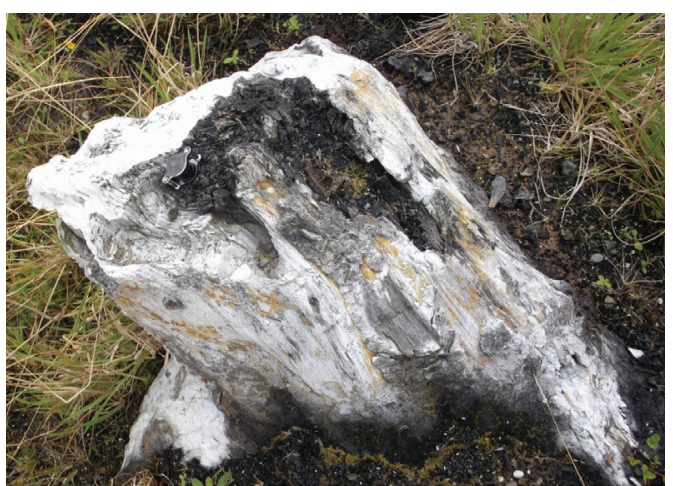

Figure I. A rooted stump at Mataura Coal Mine that looks much like a modern stump. Hand lens for scale. Photograph: Mathew Vanner.'

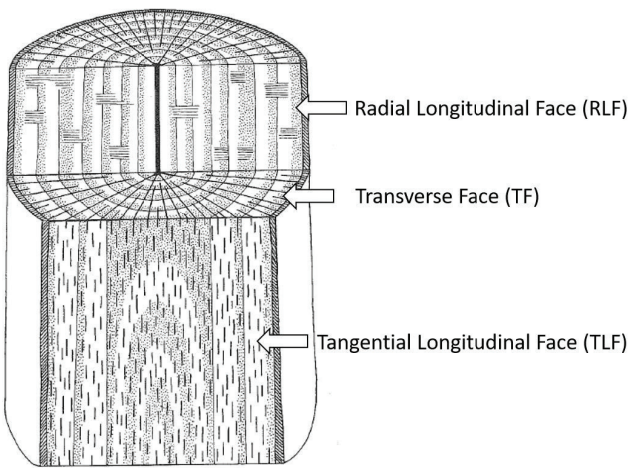

Figures 2. Block model of a trunk showing the three orientations used in wood anatomy.

Adapted from Wilson and White, The Anatomy of Wood, (1986: Figure 2). ${ }^{2}$ 
Once exposed, it is possible to study these ancient stone trees in order to discover which modern family or genera they were most closely related to. This is done by taking sections at different orientations - transverse, tangential and radial - which give three different views of the fossil cellular structure. These sections are carefully ground until they are less than a hair's width across. The structures revealed are compared to those of modern trees for identification. The identification of wood, both living and fossil, is based on the recognition of cellular features within the wood. It is easy to determine whether a sample is a gymnosperm or an angiosperm. ${ }^{3}$

In the South Island, there are many sites that yield fossil wood of different ages. It is possible to find a nearly complete record of wood from the Jurassic (200 mya) to the Quaternary (almost modern), but we find breaks in the continuity of certain genera. Araucarioxylon, ancient kauri, has been present in New Zealand for the entirety of that record. Nothofagoxylon, precursor of southern beech, has fossilised wood of Miocene age and is still present today. Casuarinoxylon- and Myrtaceae-like wood are also present in the Miocene, but died out before the end of the Pliocene.
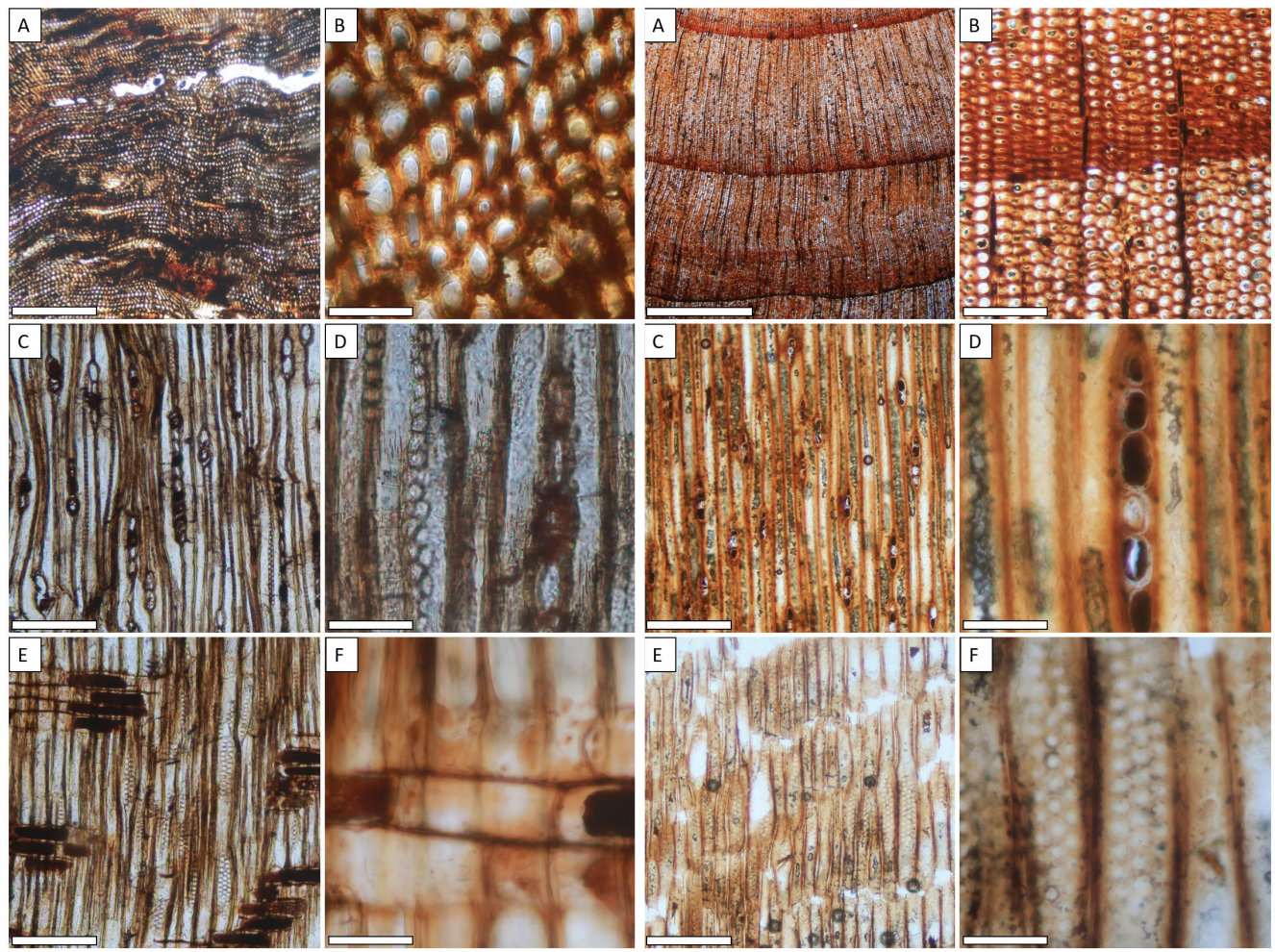

Figures 3 \& 4. The cellular structure of these specimens is gymnospermous, most likely Araucariaceae. ${ }^{4}$

The boundary between the previous year's latewood and the next year's early wood may be indistinct or distinct.

The width of a boundary can give information about the climate in which a tree grows - the wider it is, the better growing conditions the tree lived in. 

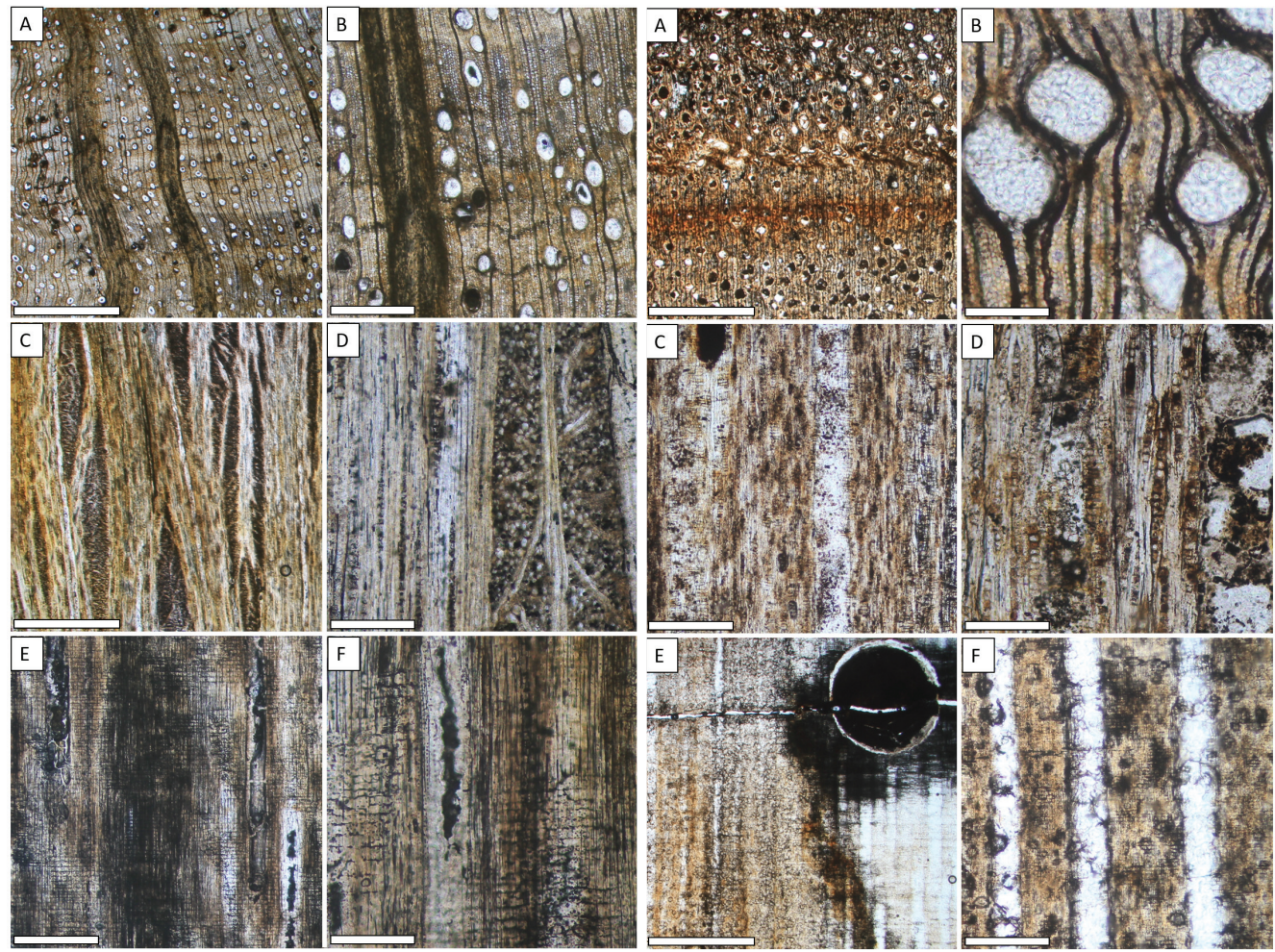

Figure 5. Casuarinaceae (left); Myrtaceae (right). The abundance of Casuarinaceae and non-New Zealand native Myrtaceae (e.g.,

Eucalyptus) in the samples was somewhat surprising, as was the low number of well-known New Zealand native genera, such as Nothofagus, given the dominance of southern beech pollen in both the fossil record and modern forests

(Bill Lee, pers. comm.). Nothofagus wood readily decays, which may account for this.

\section{A PETRIFIED SAMPLER}

\section{Pam McKinlay}

Artists make art out-of-hours in unusual spaces, and this was no more true than during the Covid- 19 lockdown of 2020, when I spent a couple of hundred hours on a free-weaving response to the petrified wood samples from Mathew Vanner's research. I designed a weaving sampler using a series of experimental lifts, weft manipulation and tapestry techniques to interpret his microscope slides. The title of my work reflects both the scientific methodology involved in preparing fine slivers of petrified rock samples for microscopic examination and the weaving of short experimental blocks to depict the visual material in the slides.

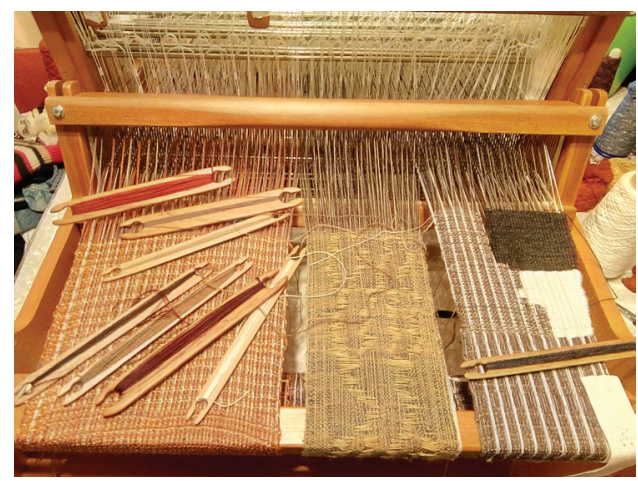

Figure 6. Weaving in progress. With reference to Mathew's sample slides, this weaving sampler records (left to right): Araucariaceae (New Vale Mine Southland),

Casurinaceae (Landslip Hill, Southland) (she-oak) and Myrtaceae - possibly Eucalyptus. 
"Geologists take it for granted that rock equals time ... I don't know of another experience that we all have in our daily lives where a solid substance represents time."

Peter Brannen

Petrified wood is rock that reveals something particular to the trees from the time and conditions when they were living. Somewhat miraculously, the textures and patterns of the live individual are captured in the fossil wood, and can be seen millennia later in the fossilised remains. Across the different species, the cumulative fragments reveal morphological similarities and distinctive characteristics at the cellular level.

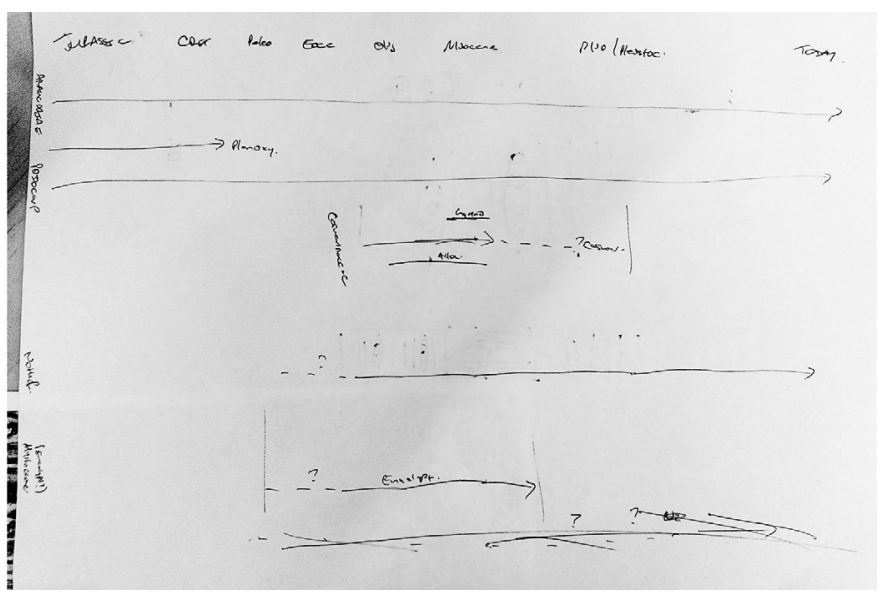

Figure 7

When I first met Mathew, we discussed the fossil wood record in the South Island, which he sketched as a timeline.

Across the top:

Jurassic, Cretaceous, Palaeocene, Eocene, Oligocene, Miocene, Pliocene/ Pleistocene (amalgamated, as much of the wood from these eras is difficult to date accurately), Today.

Along the side:

Araucariaceae, Podocarpaceae, Casuarinaceae, Nothofagus and Myrtacea (Eucalyptus).
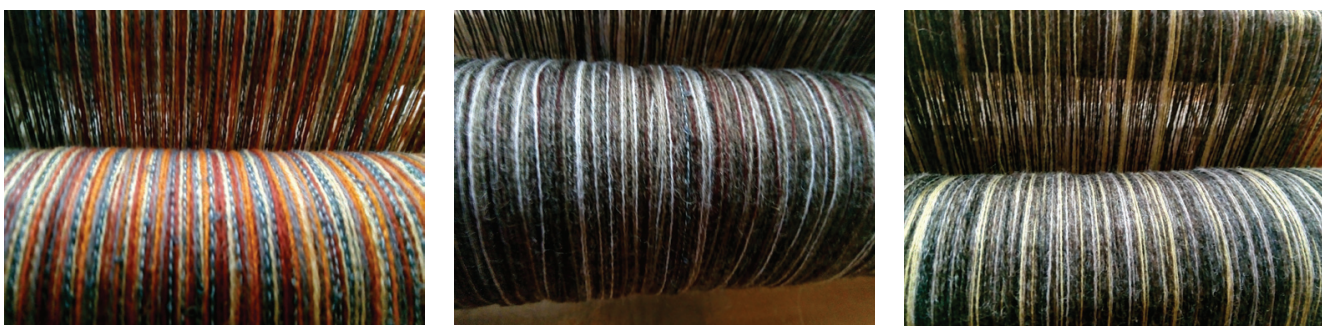

Figure 8. Colour palette derived from microscopic slides of fossil wood samples. Mathew's schema gave me the rationale and bare bones for the warp. The next step was to take the colours from the slides for the warp timeline, and the final stage was to create weft infill that would reflect the patterns in the slides.

To augment the woven panel, I also collected windfall from local monkey puzzle trees (from the Araucariaceae family), which I covered in paper clay and fired. Clay comes from areas where streams or rivers once flowed; it is made from broken-down mountains, minerals, plant life and animals from long ago. In a poetic gesture, the firing process accelerated the fossilisation process and (re)turned my windfall from living tree to rock.

In my limited time working with Mathew's research, he introduced me to the lineage of four different families that we are familiar with in our everyday lives. However, certain species within those families are under threat and face extinction events, as others have done in the past. This gave pause for thought on the fragility of the lineages I was weaving. 
As we view the stops and starts in the artwork, we might reflect on the continuity of the remaining untampered line in the weaving, the Araucariaceae lineage, and ponder its future and conservation status in the new century: threatened by kauri die-back (New Zealand); facing the constant double threat of extinction and wildfire for the remaining stand of Wollemi pine (Australia); and appearing on the endangered list and CITES Appendix for monkey puzzle trees (Chile, Argentina).

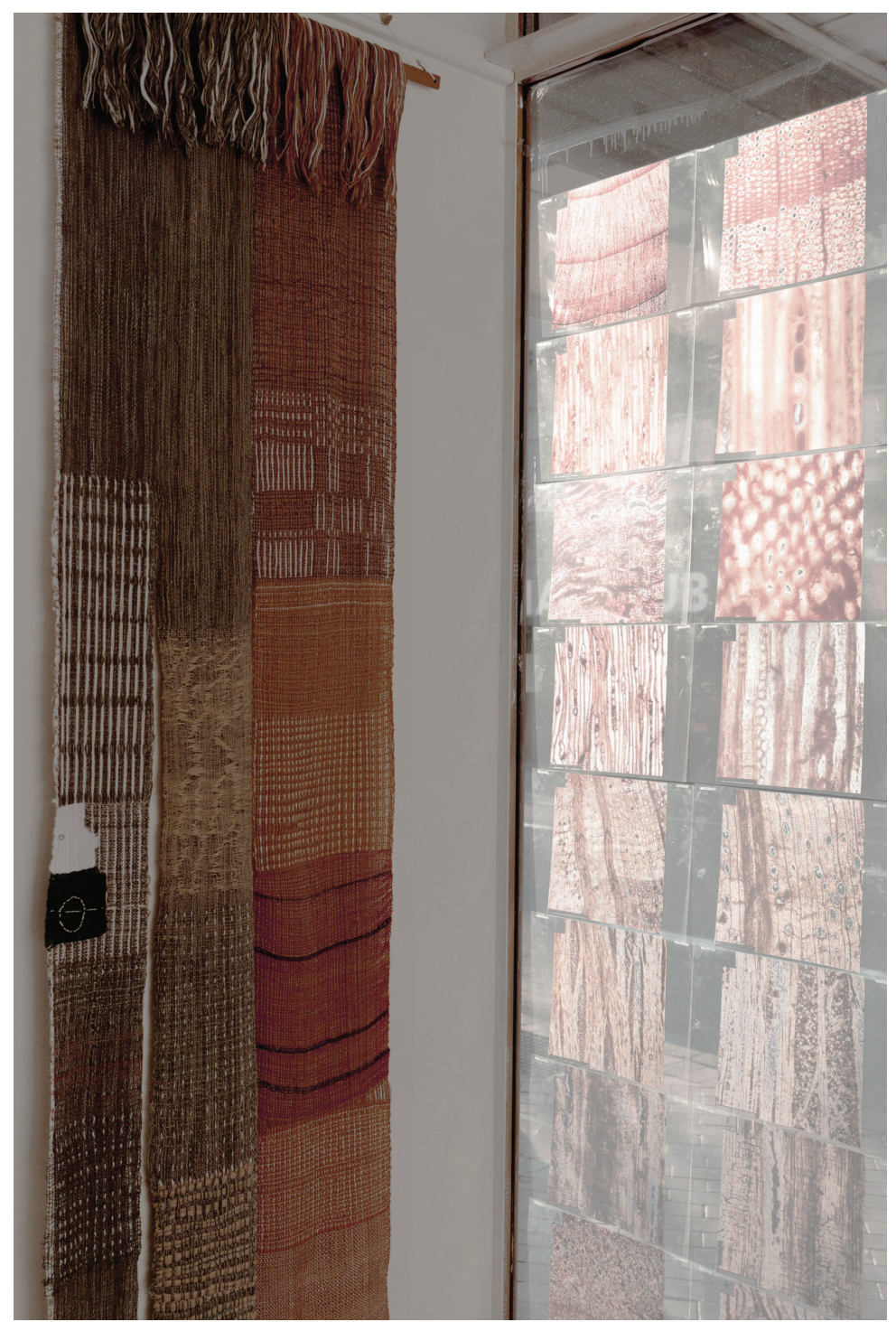

Figure 9. Pam McKinlay, Sampler: forest timelines caught in stone, 2020-21,

tapestry, single-ply and fine wool, wool silk, $510 \times 2500 \mathrm{~mm}$. Hand-woven on a I2-shaft table loom with a double warp beam, with fired clay forms representing Araucaria araucana.

Transparencies by Mathew Vanner.

Reading from top to bottom, the Araucariaceae, Casurinaceae and Myrtaceae families traverse the Jurassic to Quaternary periods in a linear paleo-botanical timeline. 
Mathew Vanner is a PhD candidate at the University of Otago. He has been interested in rocks since he was very young, collecting rocks until his pockets were full to bursting. Collecting any rock turned into a love of fossil wood after meeting a lapidarist in Southland, developing into a half-decade-long quest to identify fossil wood after meeting geologist Daphne Lee.

Pam McKinlay (ORCID ID 0000-0002-1731-6437) has a background in applied science and the history of art at the University of Otago. She collaborates with other artists in community outreach and art+science education projects on the themes of climate change, sustainability and biodiversity.

I Mathew Vanner, "Cenozoic Fossil Wood of the Southern South Island, New Zealand," (MSc thesis, University of Otago, 20 I7).

2 KWilson K and DJB White. The Anatomy of Wood: its Diversity and Variability, (London: Sobart and Son Ltd. 1986), Figure 2.

3 Ibid., p. 22. For gymnosperms, the comparison data for the New Zealand native species was taken from BA Meylan and BG Butterfield, The structure of New Zealand woods. New Zealand Department of Scientific and Industrial Research, 1978, Wellington. Data for other species was extracted from several publications, including RT Patton, "Anatomy of Australian Coniferous Timbers", Proceedings of the Royal Society of Victoria, 1927, 6(I): I-16 and P Greguss, Identification of Living Gymnosperms on the Basis of Xylotomy, Akadémiai Kiadó Budapest, 1955 and P Greguss, Xylotomy of the Living Conifers, Akadémiai Kiadó Budapest, 1972. For angiosperms, the features noted are listed in the International Association of Wood Anatomists softwood catalogue (IAWA Committee, 1989) - Inside Wood website at https://insidewood.lib.ncsu.edu/search? I .

$4 \quad$ Vanner, "Cenozoic Fossil Wood." See discussion at 8.3.1: Araucariaceae, families and higher taxa including non-native Araucaria (Wollemi pine) a remnant population of which survives perilously in New South Wales, Australia.

5 Peter Brannen, "Glimpses of a Mass Extinction in Modern-day Western New York," in The Best American Science and Nature Writing 2019, ed. Sy Montgomery (Boston: Houghton Mifflin Harcourt, 2019), 26. 